\title{
Observations of unusual fast-ice conditions in the southwest Ross Sea, Antarctica: preliminary analysis of iceberg and storminess effects
}

\author{
Kelly M. BRUNT, Olga SERGIENKO, Douglas R. MACAYEAL \\ Department of Geophysical Sciences, University of Chicago, 5734 South Ellis Avenue, Chicago, IL 60637, USA \\ E-mail: kbrunt@uchicago.edu
}

\begin{abstract}
Massive tabular icebergs $\left(\sim 1000 \mathrm{~km}^{2}\right.$ surface area, $\sim 1011 \mathrm{~kg}$ mass $)$ arrived in the southwest Ross Sea in early 2001 where they remained relatively immobile for the next 4 years. During the period of their presence, extensive landfast sea ice (fast ice) waxed and waned along the Victoria Land coast, with maximum coverage exceeding typical coverage prior to the arrival of the icebergs by a factor of 5 . The purposes of this study are to determine (1) whether the extensive 'iceberg blockade' extending from Ross Island to Drygalski Ice Tongue was indeed, as intuition suggests, responsible for the unusual fast-ice conditions, and (2) how storm frequency, intensity and seasonal timing may have mitigated the effects of the icebergs. Our simple analysis of glaciological and atmospheric conditions observed during 2001-05 suggests that iceberg movement alone is not sufficient to explain fast-ice variability; and, in fact, it is the detailed interplay between storms and iceberg location that determine this variability.
\end{abstract}

\section{INTRODUCTION}

Since January 2001, a large tabular iceberg, B-15A, covering $1000 \mathrm{~km}^{2}$ of the ocean surface and exceeding $10^{11} \mathrm{~kg}$ in mass (based on radar-derived thickness of $250 \mathrm{~m}$; personal communication from D.D. Blankenship, 2004), drifted into the southwest corner of the Ross Sea, Antarctica, where, despite being constantly in motion with ocean tides, it remained until late November 2004 (Long and others, 2002; Kim and MacAyeal, 2004). This iceberg spawned others as it collided with the Ross Ice Shelf $(\mathrm{C}-16)$ and shed several smaller fragments of itself (B-15J and B-15K). The positions of $\mathrm{B}-15 \mathrm{~A}$ and its gaggle of siblings were monitored by several techniques during the 2001-05 period, including global positioning system (GPS) instruments deployed on the icebergs (Kim and MacAyeal, 2004), satellite radar imagery (e.g. SeaWinds on QuikScat; personal communication from D.G. Long, 2004) and passive satellite imagery such as the moderate resolution imaging spectroradiometer (MODIS; e.g. Scambos and others, http://nsidc.org:80/data/ nsidc-0002.html) and Defense Meteorological Satellite Program (DMSP).

Figure 1 displays a representation of B-15A's location at the end of the 4 year period of gyration (labeled 'July 2004') as well as a sequence of positions observed during its departure from the region over the period November 2004September 2005, the latter date being when it rounded Cape Adair and exited the Ross Sea (leaving behind only C-16 and B-15J). During the initial northward passage of B-15A along the coast of the western Ross Sea, its long, $140 \mathrm{~km}$ axis was oriented parallel to the coast (Fig. 1). As it approached Drygalski Ice Tongue (Fig. 1) it formed a barricade in combination with C-16 and B-15K that completely encircled a large region within the southwestern Ross Sea (Fig. 1).

Sea-ice conditions during the 2001-05 period in the region immediately west of $\mathrm{B}-15 \mathrm{~A}$ and its siblings were unusual, and exhibited greater variability, relative to the period of time prior to the iceberg's arrival. An illustration of the unusual nature of conditions is provided by Figure 2, where a MODIS image from January 2005 displays the prominent build-up of fast ice in a region normally ice-free during the summer melt season. Also shown in this figure is an area of broken, mobile sea ice (referred to as pack ice) which had several days earlier been part of the integrated

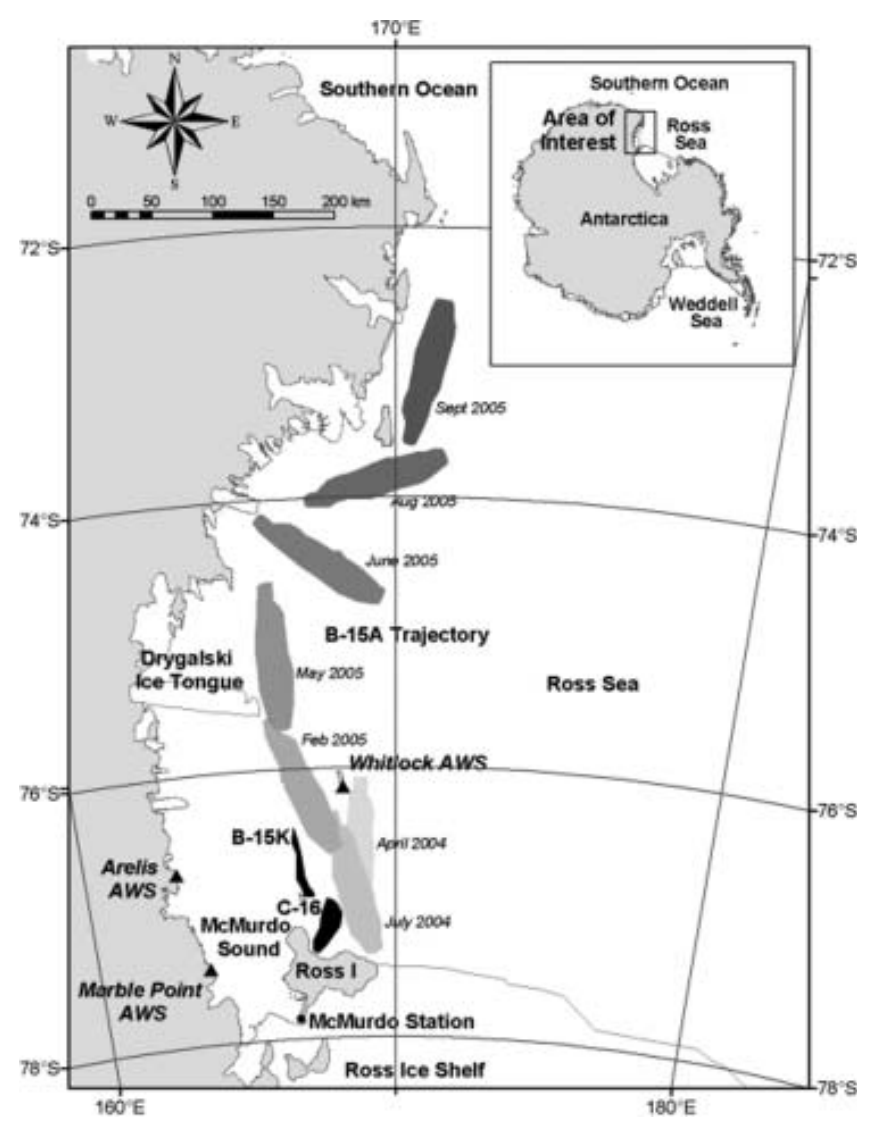

Fig. 1. Massive tabular icebergs and automatic weather station (AWS) locations (as triangles) in the southwest Ross Sea, Antarctica. The trajectory of B-15A is shown. 


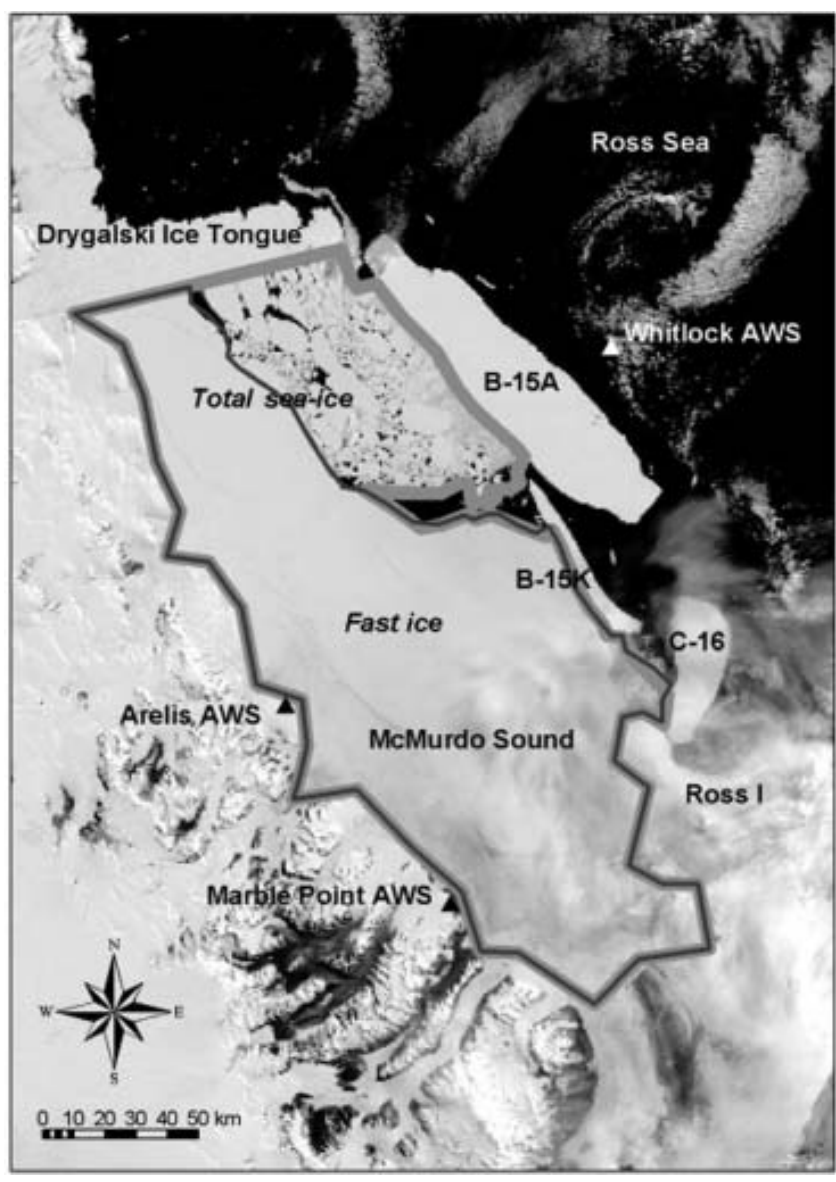

Fig. 2. Characteristic MODIS image displaying the iceberg blockade during January 2005, when the closure of the blockade was most effective. Outlined are two regions within the blockade identified using the subjective methodology described herein as either fast-ice or pack-ice covered.

fast-ice cover, and which had broken up as a result of weather conditions. The broken pack ice displayed in Figure 2 was transformed from fast ice in the matter of only a day or two, and the abruptness of this break-up constitutes a main style of variability in the sea-ice conditions over the 2001-05 period.

A typical year in the sequence of sea-ice conditions of the area blockaded by the icebergs would consist of fast-ice build-up during the austral autumn, winter and early spring, interspersed with occasional, sudden blow-outs of this fast ice as a result of storms. During the late austral spring and summer the fast ice would occasionally fail to melt or be cleared away by summer storms, and this led to a build-up of multi-year sea ice in the region, particularly in McMurdo Sound. Observations of this variability come from the usual sources (e.g. satellite imagery and radar data (Drinkwater and others, 2004; T.A. Scambos and others, http://nsidc.org:80/ data/nsidc-0002.html)), as well as non-traditional sources such as the US Coast Guard icebreaker fleet that struggled to cope with maintaining an open shipping channel in the area (Abood and others, 2005).

In contrast to numerous studies of Antarctic sea-ice extent and variability prior to recent iceberg calving in the Ross Sea (e.g. Zwally and others, 2002; Parkinson, 2004; Nihashi and others, 2005), studies of the effects of icebergs are limited and most were done in the 1980s in response to calving in the Weddell Sea (e.g. Foldvik and others, 1980;

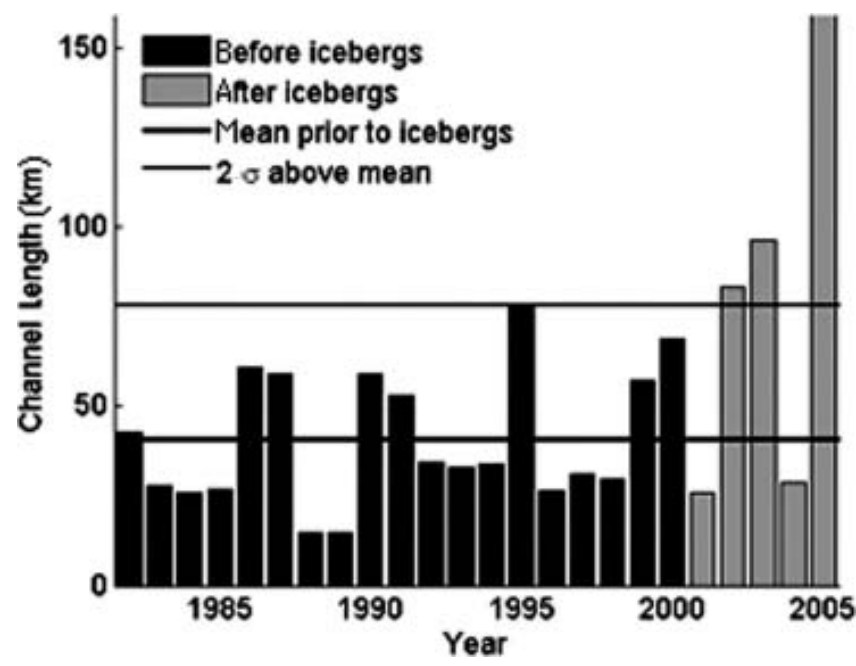

Fig. 3. The length of the US Coast Guard icebreaker channel to McMurdo station (Abood and others, 2005).

Josberger and Neshyba, 1980; Orheim, 1980). Nøst and Østerhus (1998) have studied the effects of three icebergs which calved from Filchner Ice Shelf east of Berkner Island in 1986, and which subsequently became grounded just north of the shelf. Their study found that sea-ice concentration increased, sea-ice production decreased and sea-ice mobility decreased during the presence of the icebergs. They also showed that there were significant changes to the hydrographic properties of the Weddell Sea in response to these icebergs, and cited, as a principal reason, the prevention of sea-ice drift and incoming sea swell by the iceberg barrier. More recently, Arrigo and others (2002) and Arrigo and Van Dijken (2003) reported similar effects to those reported for the Weddell Sea within the Ross Sea. Their study involved conditions immediately following the calving of B-15 and C-19 in 2000 and 2002, respectively. Using daily Special Sensor Microwave Imager (SSM/I) and Scanning Multichannel Microwave Radiometer (SMMR) imagery, they found extraordinarily high sea-ice concentrations in the southwest Ross Sea during 2002-03, which subsequently had strong impacts on the biological productivity of the region.

Here we present a preliminary overview of sea-ice conditions in the southwest Ross Sea between January 2001 and May 2005, with particular emphasis on the period October 2004-May 2005, when B-15A and its siblings B-15K and C-16, together with Drygalski Ice Tongue, (Fig. 1) formed an almost perfect physical barrier (Fig. 2) isolating the southwestern Ross Sea from the ocean beyond. The purposes of our overview are (1) to determine the extent to which the blockade formed by icebergs, particularly during the period when B-15A was moving north during late 2004 and early 2005, is sufficient to explain the extent of fast ice in the region, and (2) to examine using simple meteorological observations the interplay between storms and iceberg position in determining the often abrupt changes in fast-ice coverage. While it may seem intuitively obvious that an iceberg blockade would enhance fast-ice coverage and variability, our emphasis is on examining the role of other variables, particularly measures of atmospheric storminess, that are needed to explain anomalous sea-ice conditions over the period of study. 


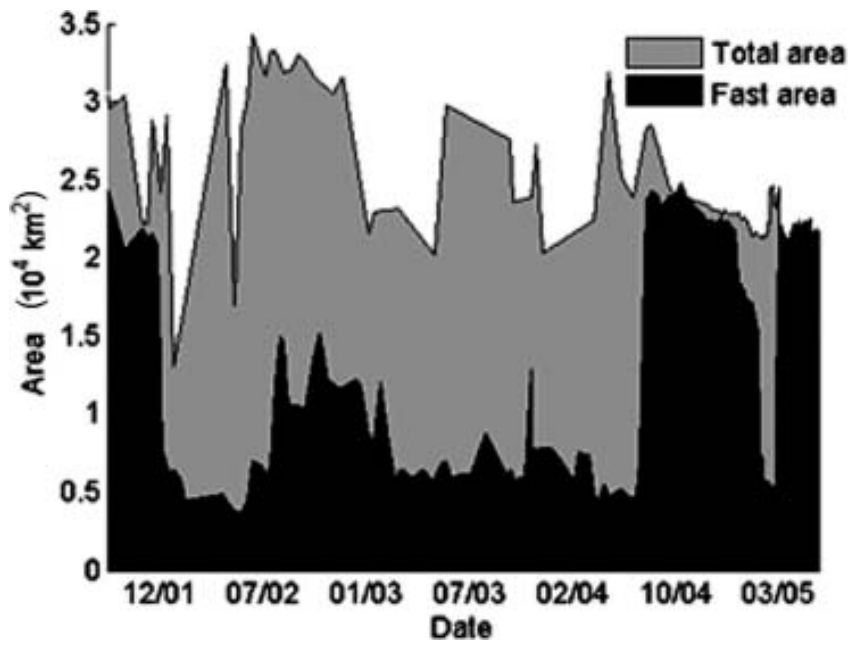

Fig. 4. Fast-ice area (black shaded area) and total sea-ice area (gray shaded area) derived from MODIS and DMSP images. Dates are $\mathrm{mm} / \mathrm{yy}$.

\section{OBSERVATIONS AND METHODS}

\subsection{Historical icebreaker observations}

Concurrent with the presence of B-15A and its siblings near the entrance to McMurdo Sound (Fig. 1), extended first-year sea ice and the persistence of multi-year sea ice has made icebreaker operations in the area more challenging. One unorthodox measure of the sea-ice conditions associated with these logistical challenges is the length of the sea-ice shipping channel required to be maintained ice-free for ship traffic. Historical data (Fig. 3) compiled by the US Coast Guard in response to a US National Research Council study of icebreaker operations (Abood and others, 2005) show that the length of the icebreaker channel needed to reach McMurdo Station (a scientific station run by the US National Science Foundation) exceeded the 19 year mean length of years prior to the arrival of the icebergs (prior to 2001) by twice the standard deviation $(2 \sigma)$ in three years out of five. In contrast, before the icebergs arrived in the area, the channel exceeded the mean by $2 \sigma$ only in one year in nineteen. The maximum channel length during the entire 24 year period was achieved in 2005, when it was more than three times larger than the average value. Abood and others' (2005) report also details the trends of multi-year and thick $(>180 \mathrm{~cm})$ sea ice along the icebreaker channel in McMurdo Sound, and documents an overall increase during the past 4 years of all sea-ice categories.

\subsection{Satellite image analysis of fast-ice and pack-ice area}

To quantify the effect of the iceberg blockade on sea ice in the southwestern Ross Sea, we introduce the following geographic parameters that are readily determined from satellite imagery using, for example, Geographic Information System (GIS) software:

the relative length (\% of total length) of combined gaps within the iceberg blockade through which open water can be reached from inside the blockade area,

the area $\left(\mathrm{km}^{2}\right)$ of fast ice within the region enclosed by the blockade, and

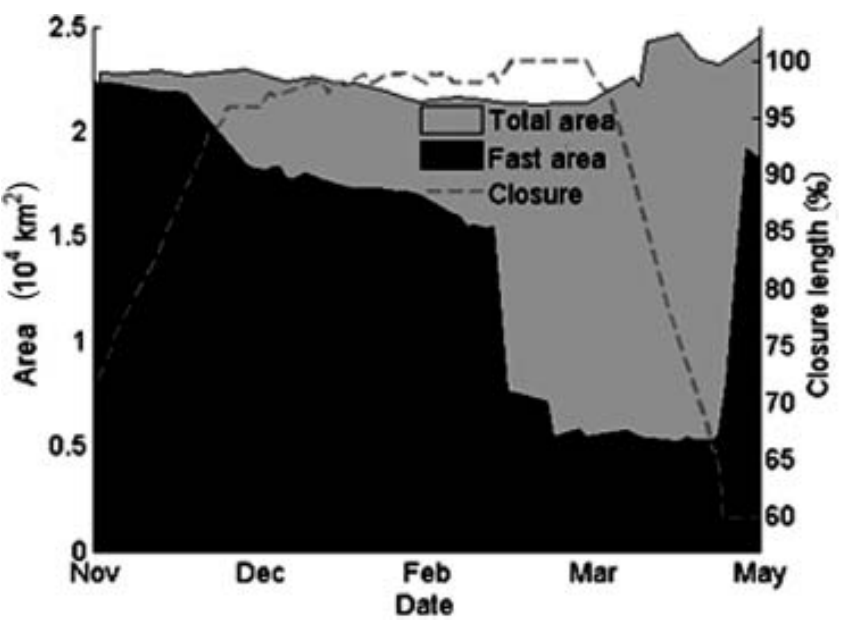

Fig. 5. Sea-ice area (fast-ice area shaded black and total sea-ice area shaded gray) in McMurdo Sound and closure of McMurdo Sound (dashed line) in November 2004-June 2005 from MODIS and DMSP images. Left axis is sea-ice area $\left(\mathrm{km}^{2}\right)$; right axis is closure (\%). Drops in fast-ice area are due to storms in the beginning of January and February 2005.

the area $\left(\mathrm{km}^{2}\right)$ of broken, mobile pack ice within that region (e.g. as shown in Fig. 2).

To measure the above parameters, several subjective decisions were made, the most uncertain of which was the discrimination of fast ice from broken, mobile forms of sea ice (that we refer to as pack ice). For periods when satellite imagery in the visible band was cloud-free and well illuminated (e.g. during austral summer), fast ice was readily identified by the consistency of its relatively lead-free, snowcovered appearance that persisted from day to day. An example of where this identification was relatively certain is presented in Figure 2, where the areas of fast ice and broken pack ice are outlined.

The subjective discrimination between fast ice and other sea-ice categories is much more uncertain in images using thermal bands of MODIS, typically during the austral winter, because the resolution necessary to detect leads and other signs of mobility is much reduced. To cope with the reduced resolution, we relied on subjective decision-making focused on open-water voids and linear flaws (of an undetermined nature, but presumably leads and ridges) in the image to determine when they became sufficiently unchanged from day to day to suggest that the system had refrozen. Clearly, this level of subjectivity is anachronistic relative to modern sea-ice discrimination techniques (e.g. Parkinson, 2004); however, the simplicity of the present study's objective led us to avoid the more difficult, objective sea-ice identification methods.

The parameters presented in the above list were quantified from a selection of relatively cloud-free MODIS and DMSP images using GIS software following the usual methods, i.e. digitizing map polygons. The areas of fast ice and pack ice derived using the above procedure for the 2001-05 period are shown in Figures 4 and 5.

\subsection{Storm index}

Detailed analysis of the MODIS images described above showed that periods when the fast-ice area was generally low corresponded with storm events that led to abrupt 


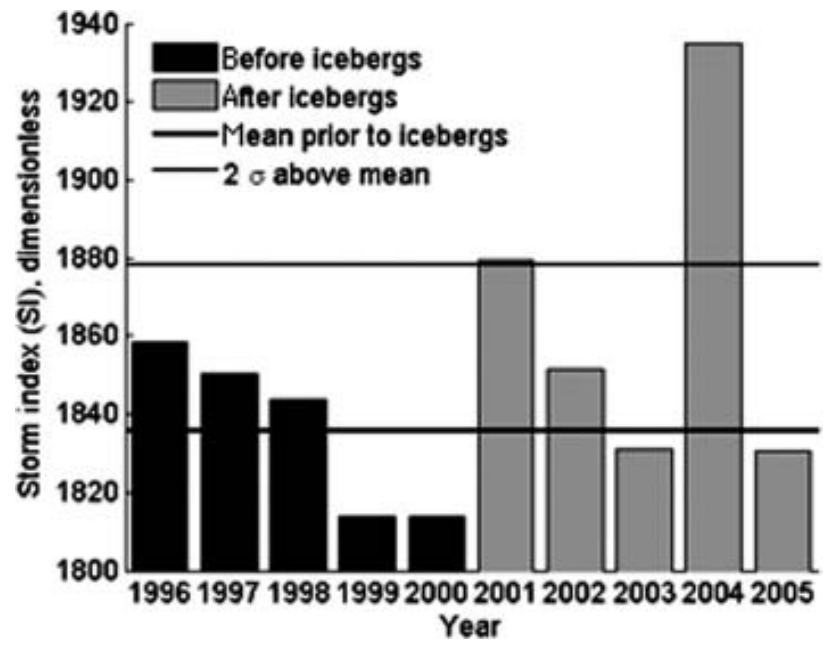

Fig. 6. Storm index derived using Equation (1) from the Marble Point AWS data.

break-up, mobilization and clearing by flow through the various gaps in the iceberg blockade. To quantify storminess, and to assess the level to which it competes with the iceberg-blockade effect in determining sea-ice conditions, we introduce a 'storm index' that describes frequency and strength of storms. Our storm index was developed in the context of this study and is not based on other usual storm indices used in other meteorological applications.

To develop a storm index which could be compared with the iceberg blockade parameters described in section 2.2, we compiled temperature, pressure and wind-speed data from three automatic weather stations (AWSs) located in the vicinity of the iceberg blockade (Fig. 1; Stearns, 1997). Analysis of these data showed that meteorological readings from separate stations strongly co-vary, and that a sufficient but simple measure of the atmospheric regime could be derived using only a single station, Marble Point (Fig. 1). Accordingly, we used data from Marble Point, because these data span a longer time period and have fewer gaps than data from Whitlock and Arelis stations.

A climatologic mean of atmospheric conditions (temperature, pressure and wind speed) was created from the 11 year AWS record at Marble Point spanning 1995-2005. All of the atmospheric parameters during the entire 11 year period (atmospheric pressure, temperature, wind speed and direction) were within $2 \sigma$ limits of the climatologic means, although wind speed was consistently low, except for several events lasting only a few days. This 11 year record constituted the data from which our storm index was derived.

To define the storm index, we compared MODIS and DMSP images with the atmospheric record from Marble Point to determine the characteristics of weather conditions most influential in breaking up fast ice. These conditions were found to be characterized by the simultaneous occurrence of low pressure and an anomalous temperature. By 'anomalous temperature' we mean a temperature deviation that can be either warmer or colder than the climatologic mean depending on season. The temperature anomaly we define is warmer than the climatologic mean during the austral winter or fall (when it is normally cold), and is colder during the austral spring or summer (when it is normally warm).
Using the above consideration as a guide, we construct a non-dimensional storm index (SI), in the following way:

$$
\begin{aligned}
\text { SI }=\alpha\left[\sum_{\substack{P<\langle P\rangle \cap T>\bar{T} \\
\text { winter }}}(\langle P\rangle-P)(T-\bar{T})\right. \\
\left.+\sum_{\substack{P<\langle P\rangle \cap T<\bar{T} \\
\text { summer }}}(\langle P\rangle-P)(\bar{T}-T)\right],
\end{aligned}
$$

where $\alpha$ is a coefficient $\left(1 \mathrm{~Pa}^{-1}{ }^{\circ} \mathrm{C}^{-1}\right)$ designed to render the index dimensionless, $\langle P\rangle$ is the 60 day running mean pressure, $P$ is the mean daily pressure, $\bar{T}$ is the 30 day running mean temperature and $T$ is the mean daily temperature. The choice to use 60 and 30 day running means for pressure and temperature, respectively, was arbitrary, and designed to account for the typical difference in timescale with which these two atmospheric parameters vary. The storm index derived from Equation (1) is displayed in Figure 6.

\section{DISCUSSION}

As follows from Figure 4, the majority of the $35000 \mathrm{~km}^{2}$ area blockaded by the icebergs was covered by sea ice (either fast ice or mobile pack ice) throughout the period of the iceberg blockade. Before the austral winter of 2004, the area of fast ice hovered around $5000 \mathrm{~km}^{2}$. After July 2004, fast ice grew to fill almost the entire region, attaining over $25000 \mathrm{~km}^{2}$ coverage at its maximum. During January and February 2005, this extraordinary all-time maximum coverage reduced in a step-like fashion, with two reduction steps separated by about a month, to levels more typical during prior years, and then almost immediately advanced to the maximum level (where, as an aside, it persists in January 2006, beyond the date of our data analysis). During the period of high fast-ice coverage, the step-like reduction of coverage and the almost immediate resurgence of coverage, the long axis of iceberg B-15A almost completely closed the iceberg blockade (Figs 1 and 5), suggesting that the blockade led to the rapid resurgence. This demonstrates the most intuitive effect of the iceberg blockade, i.e. to prevent the flushing of sea ice in the aftermath of storms and thereby to allow rapid refreezing of the pack ice after being broken up by storms.

Figure 6 shows the storm index over the 1996-2005 period. During the period of the iceberg blockade, the storm index was higher than during years before the icebergs arrived. It is beyond the scope of this study to speculate whether the apparent increased storminess is significant and, if so, whether it was somehow related to the presence of the icebergs (e.g. the icebergs caused extra surface heat-flux gradients to induce storms, or, alternatively, increased storminess led to the icebergs remaining in the area). It should be noted, however, that during the years with the highest storm index, i.e. where the storm index exceeded $2 \sigma$ of the 11 year average, the length of the US Coast Guard icebreaker channel (Fig. 3) correspondingly failed to exceed $2 \sigma$ of the corresponding 24 year mean. The maximum storm index was observed in 2004, and the length of a channel was minimal despite the developing blockade by the icebergs. This comparison demonstrates the complex interplay between weather conditions and the presence and 
location of icebergs, and highlights the difficulty of accepting simple, intuitive explanations for the cause of sea-ice variability during the period of iceberg occupation.

\section{CONCLUSION}

The unusual fast-ice coverage and variability in the southwestern Ross Sea during the 2001-05 period coincided with an iceberg blockade cutting off the study region from the open ocean beyond. Equally important, however, is the fact that this same period experienced unusual atmospheric conditions, most notably recognized by an increase in storminess as represented by a storm index derived in this study. A simple comparison of the various time series of fastice coverage, iceberg blockade parameters and the storm index shows that the simple, intuitive notion of the geographical isolation of the region by the iceberg blockade is insufficient to explain both the extent and variability of the fast-ice coverage. The preliminary analysis here implies that the principal effect of the iceberg blockade is to modulate the influence of storms that would otherwise flush the pack ice from the region. The main effect of the icebergs is thus to allow rapid reformation of fast ice in the wake of storms that would otherwise clear the sea ice.

\section{ACKNOWLEDGEMENTS}

This research was supported by US National Science Foundation grant 0229546. Thanks are given to Young-Jin Kim and B. Brunner for help with data analysis and presentation.

\section{REFERENCES}

Abood, K., K. Bernard, J. Berner, J. Nagy, R. Hayes and R.E. Young. 2005. Mission analysis report: polar ice operations. Washington DC, US Coast Guard. Commandant Office (G-OPN). (GS23F-025K.)
Arrigo, K.R. and G.L. van Dijken. 2003. Impact of iceberg C-19 on Ross Sea primary production. Geophys. Res. Lett., 30(16), 1836. (10.1029/2003GL017721.)

Arrigo, K.R., G.L. van Dijken, D.G. Ainley, M.A. Fahnestock and T. Markus. 2002. Ecological impact of a large Antarctic iceberg. Geophys. Res. Lett., 29(7), 81-84.

Drinkwater, M.R., R. Francis, G. Ratier and D.J. Wingham. 2004. The European Space Agency's Earth Explorer Mission CryoSat: measuring variability in the cryosphere. Ann. Glaciol., 39, 313-320.

Foldvik, A., T. Gammelsröd and Y. Gjessing. 1980. Measurements of the radiation temperature of Antarctic icebergs and the surrounding surface water. Ann. Glaciol., 1, 19-22.

Josberger, E.G. and S. Neshyba. 1980. Iceberg melt-driven convection inferred from field measurements of temperature. Ann. Glaciol., 1, 113-117.

Kim, Y. and D.R. MacAyeal. 2004. Iceberg surveillance: preliminary analysis of iceberg drift data. [Abstract C31B-0315.] EOS Trans. AGU, 85(47), Fall Meet. Suppl.

Long, D.G., J. Ballantyne and C. Bertoia. 2002. Is the number of icebergs really increasing? EOS Trans. AGU, 83(42), 469, 474.

Nihashi, S., K.I. Ohshima, M.O. Jeffries and T. Kawamura. 2005. Sea-ice melting processes inferred from ice-upper ocean relationships in the Ross Sea, Antarctica. J. Geophys. Res., $110(2), 1-12$.

Nøst, O.A. and S. Østerhus. 1998. Impact of grounded icebergs on the hydrographic conditions near the Filchner Ice Shelf, Antarctica. In Jacobs, S.S. and R.F. Weiss, eds. Ocean, ice and atmosphere: interactions at the Antarctic continental margin. Washington, DC, American Geophysical Union, 269-286. (Antarctic Research Series 75.)

Orheim, O. 1980. Physical characteristics and life expectancy of tabular Antarctic icebergs. Ann. Glaciol., 1, 11-18.

Parkinson, C.L. 2004. Southern Ocean sea ice and its wider linkages: insights revealed from models and observations. Antarct. Sci., 16(4), 387-400.

Stearns, C.R. 1997. Ross Island area wind field. Antarct. J. US, 5(33), 181-182.

Zwally, H.J., J.C. Comiso, C.L. Parkinson, D.J. Cavalieri and P. Gloersen. 2002. Variability of Antarctic sea ice 1979-1998. J. Geophys. Res., 107(C5), 3041. (10.1029/2000JC000733.) 